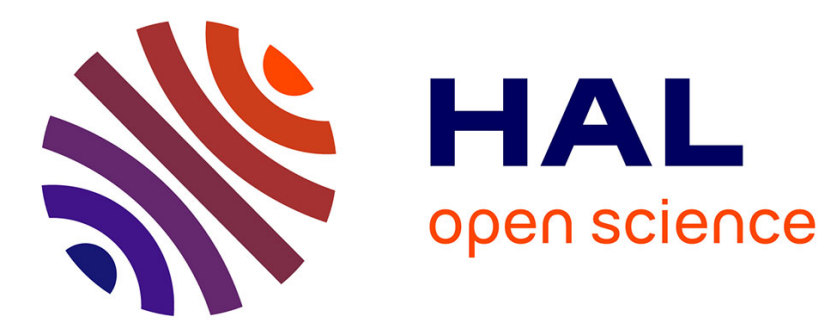

\title{
Robotic cell for custom finishing operations
}

Bojan Nemec

\section{To cite this version:}

Bojan Nemec. Robotic cell for custom finishing operations. International Journal of Computer Integrated Manufacturing, 2008, 21 (01), pp.33-42. 10.1080/09511920600667341 . hal-00513374

\section{HAL Id: hal-00513374 \\ https://hal.science/hal-00513374}

Submitted on 1 Sep 2010

HAL is a multi-disciplinary open access archive for the deposit and dissemination of scientific research documents, whether they are published or not. The documents may come from teaching and research institutions in France or abroad, or from public or private research centers.
L'archive ouverte pluridisciplinaire HAL, est destinée au dépôt et à la diffusion de documents scientifiques de niveau recherche, publiés ou non, émanant des établissements d'enseignement et de recherche français ou étrangers, des laboratoires publics ou privés. 


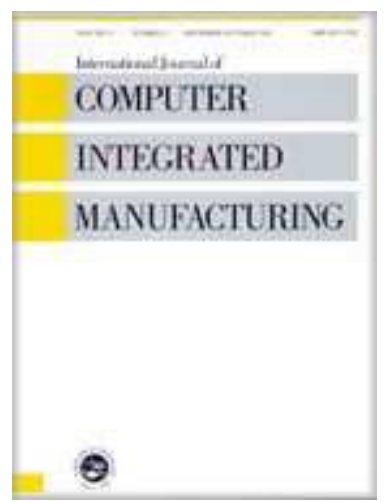

\section{Robotic cell for custom finishing operations}

\begin{tabular}{|r|l|}
\hline Journal: & International Journal of Computer Integrated Manufacturing \\
\hline Manuscript ID: & TCIM-2005-IJCIM-0037.R2 \\
\hline Manuscript Type: & Original Manuscript \\
\hline Date Submitted by the \\
Author: & $14-$ Feb-2006 \\
\hline Complete List of Authors: & Nemec, Bojan; Jozef Stefan Institute, . \\
\hline Keywords: & ROBOT CONTROL, ROBOTIC CELL, ROBOT APPLICATIONS \\
\hline Keywords (user): & \\
\hline
\end{tabular}

\section{\) ScholaroNE"}




\title{
Robotic cell for custom finishing operations
}

\author{
Bojan Nemec and Leon Žlajpah \\ Jozef Stefan Institute \\ Jamova 39 \\ 1000 Ljubljana \\ Slovenia
}

Tel: 0038614773565

e-mail : bojan.nemec@ijs.si

\begin{abstract}
:
Finishing operations in shoe manufacturing process comprises operations such as application of polishing wax, polishing cream and spray solvents, and brushing in order to achieve high gloss. These operations require skilled worker and are generally difficult to automate due to the complex motion trajectories. The paper describes a robotic cell for finishing operations in a custom shoe production plant. Such customization of shoe production should allow production of small batches of shoes of the same type. This requires automatic set up and adaptation of the production line. To meet these requirements, a CAD system for automatic generation, optimization and validation of motion trajectories was integrated into a robotic cell. In automatic trajectory generation some of the major problems are limitations posed by the robot joint limits, robot singularities and environment obstacles. These problems were solved using the kinematic redundancy of the robot manipulator.
\end{abstract}

\section{INTRODUCTION}

The paper presents research undertaken as a larger multidisciplinary research project EUROShoE with an overall aim in redefining the concept of the shoe as a product and of its production (ITIA-CNR 2003). One of the main issues in the project is the 
transformation from a mass produced goods to a mass customized products. This product evolution goes in parallel with the transformation of the footwear company into an extended and agile enterprise capable of handling the complexity deriving from the direct involvement of a consumer in the design and the manufacturing process of the shoes he is going to buy. Such a radical change in the product nature forces a complete revision of processes that support various phases of the product life cycle (design, production, sale and distribution, use, dismissal and recycling). In order to meet all requirements deriving from the mass customization, the production has to be highly automated by means of flexible automation, assuring best quality, high flexibility and avoiding human operators wherever it is possible (Dulio, Boër 2004). EUROShoE project involves 34 partners, covering all processes from the planning and design to the production and distribution. Jozef Stefan Institute, Department for Automatics, Biocybernetics and Robotics, joined the EUROShoE project as the last of 34 partners in July 2002. Our task was to develop the automated cell for finishing operations in the shoe production. The research phase of our task covered the required analysis of the existing manual finishing process, the determination of the required technologies including the selection of an appropriate robot and work cell components, and finally, the development and the implementation of the process control algorithms. Final result was a prototype of the automated cell for finishing operations, installed in IPP in Vigevano, Italy.

\section{ANALYSIS OF FINISHING OPERATIONS}

The analysis of the existing manual finishing process was carried out at several EUROShoE end-users partners.

The finishing process normally encompasses a variety of operations. Some of them like inserting laces, inserting cleaning insoles and applying final decorative details to the shoe do not seem to lend themselves to easy automation. Some others are normally performed by the operators by manipulating the shoes in various kinds of devices: sprayers to apply polish, brushes to clean and polish the shoe itself, felt or fabric rollers to give it the final 
glossy finishing. These operations are normally highly labour intensive and, some of them, potentially dangerous for the operators' health. (Taylor 1988)

Shoe finishing operations are normally performed on a complete shoe at the end of the assembling phase and after the last has been pulled out off the shoe. Finishing operations differ from manufacturer to manufacturer, but usually they include cleaning,retouching, polishing, examining and dispatching. Cleaning includes operations like glue removal, degreasing, removal of dirt and smudge. Retouching includes correction of scratches with brush and colour. Polishing is the most complex operation and has multiple goals, such as

- To remove the top coating colour (antique finish)

- To obtain high gloss finish

- To add a protective coating

Polishing involves polishing cream application, drying and brushing. Polishing cream can be supplied as hard wax, cream or solvent. A typical polishing cycle is composed of following operations

- Application of the polishing cream

- Drying approx $10 \mathrm{~min}$

- First brushing using hard brush, brush rotation speed 400-600 rev/min, application of filling wax on felt rollers, reperation of the irregularities of the leather

- Spraying with appropriate solvents to add protective coating

- Drying approx $10 \mathrm{~min}$

- Final polishing, using soft brushes, brush rotation speed 600-900 rev/min, application of high gloss wax on flet rollers, high gloss must be acheived

Not all mentioned operations are required on all types of shoes. For example, on shoes made of fabric or suede uppers, polishing cream should not be applied. However, typical polishing cycle comprehends all possible operations.

Cleaning, retouching and inspection process are extremely difficult to automate. Even with most advanced video recognition system it would be very difficult to identify dirt, smudge and scratches on the shoe surface. Therefore, the scope of the project were on 
the remaining finishing processes, including polishing cream application, brushing, polishing and spraying.

\section{ANALYSIS OF CONTACT FORCES IN FINISHING OPERATIONS}

Robot based polishing was investigated by many authors (Furukawa 96, Zhao 95, Tam 99, Akbari 01, Baseñez 05). However, none of them dealt with the shoe polishing and the corresponding technological parameters. One of the most important parameters is the necessary force in finishing operations which had to be estimated. For that, the contact forces between the brush and the shoe had been measured with JR3 universal force sensor. The sensor was capable of measuring forces up to $250 \mathrm{~N}$ and torques up to $20 \mathrm{Nm}$ in all three directions $\mathrm{x}, \mathrm{y}$ and $\mathrm{z}$, and was mounted on a plate with two handles, as shown in figure 1. The operator performed the required motions for the shoe brushing and polishing. The force measurement was repeated for different brushes and at different brush speeds. The results for the hard brush are presented in figures 2 and 3. As expected, the maximum force was obtained by using the hard abrasive brush at $700 \mathrm{rpm}$. The maximum estimated force was $80 \mathrm{~N}$ and the maximum torque was $12 \mathrm{Nm}$.

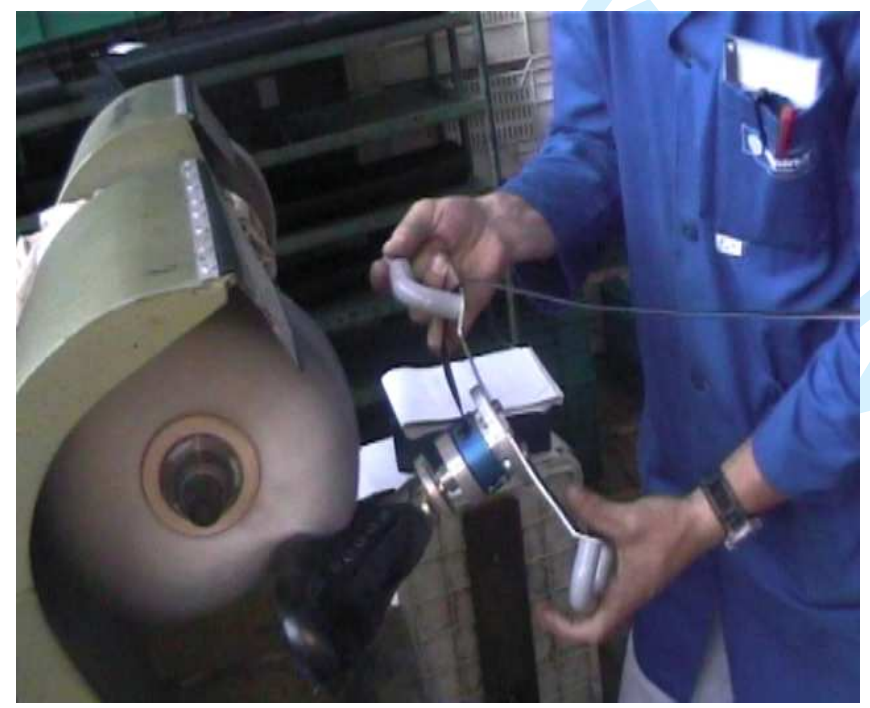

figure 1: Force measurement setup 
Nemec, Zlajpah

Robotic cell for custom finishing operations

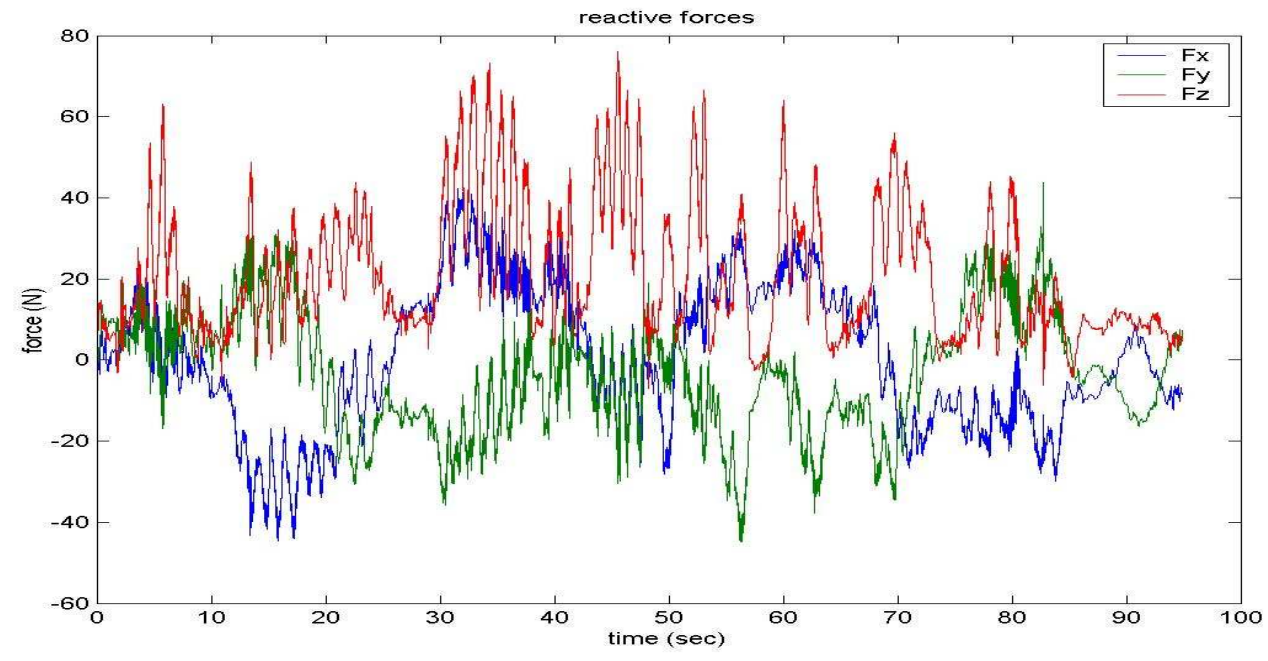

figure 2 : Reactive forces using hard brush at $700 \mathrm{rpm}$

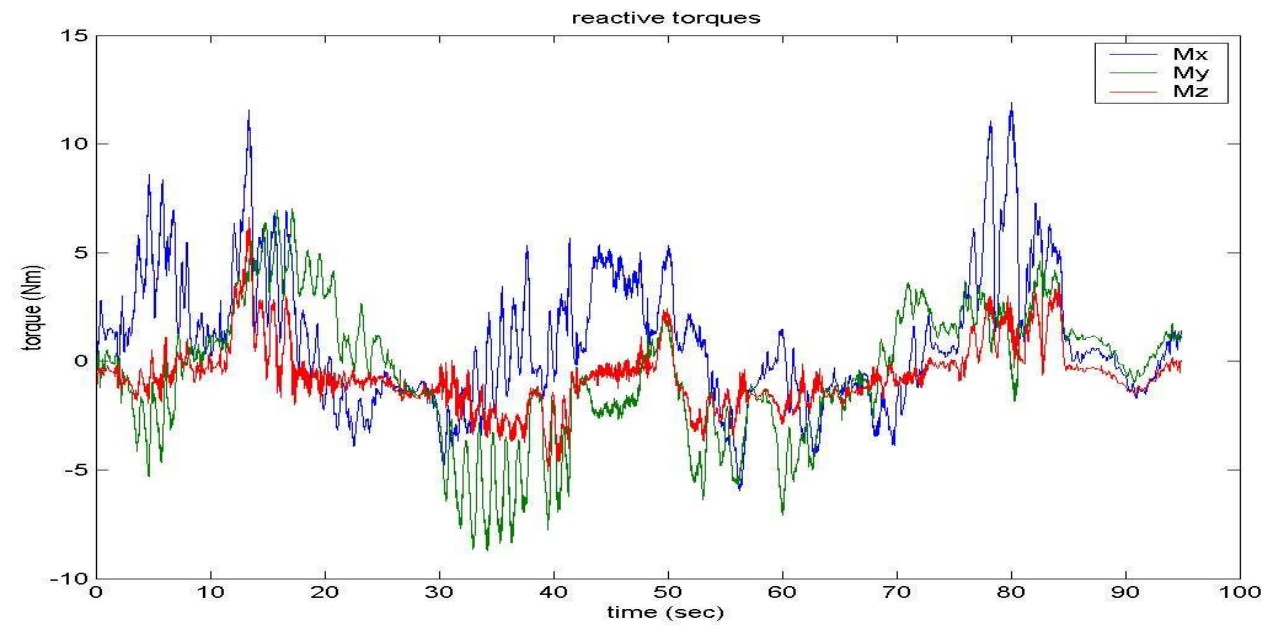

figure 3 : Reactive torques using hard brush at $700 \mathrm{rpm}$

To obtain the stiffness characteristics of the brush the force measurement was synchronised with the video analysis software, capable of tracking the selected points on the video image. Using the force measurement and the position displacement we calculated the compliance of the hard brush. The characteristic is shown in figure 4. From theses results it can be seen that the compliance can be approximated with a linear function with slope around $2.1 \mathrm{~N} / \mathrm{mm}$. This makes force control possible even without 
Nemec, Zlajpah

Robotic cell for custom finishing operations

using the force sensor providing that the overall positioning accuracy is within $1 \mathrm{~mm}$. (Hogan 1985)

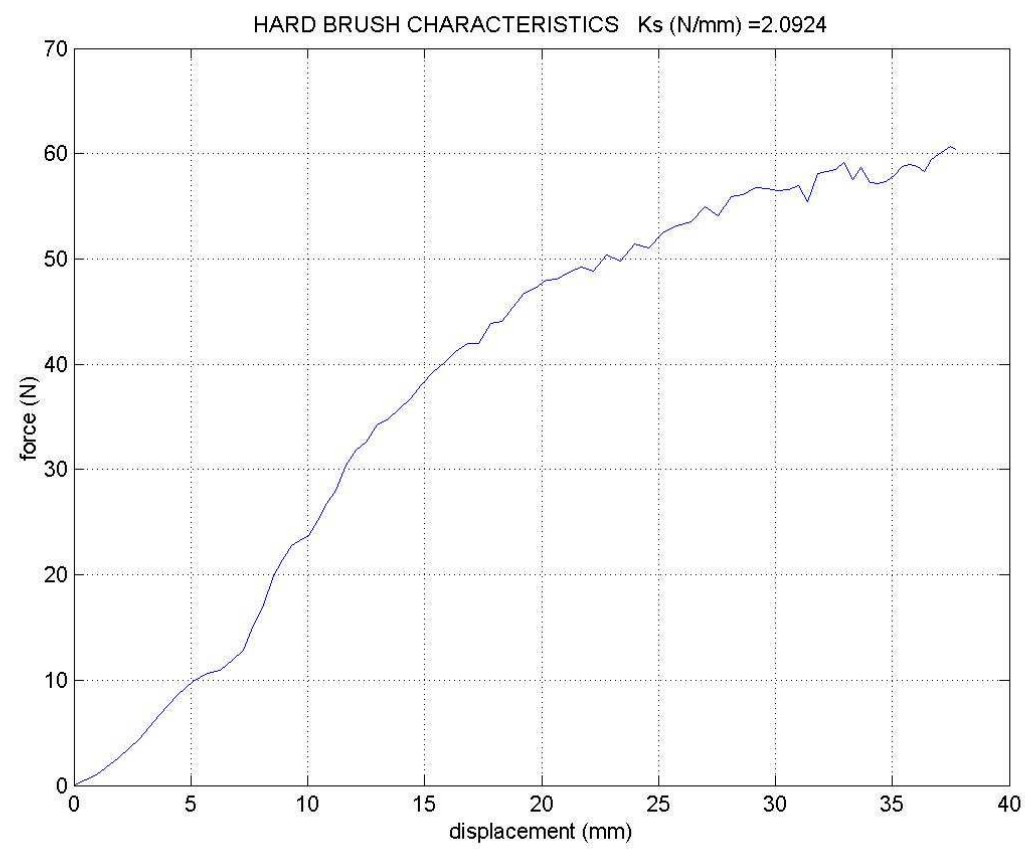

figure $4:$ Measured characteristics of the hard brush at $700 \mathrm{rev} / \mathrm{min}$

\section{DEVELOPMENT OF THE FINISHING CELL}

Based on the typical polishing cycle we designed the finishing cell which includes the following devices

- Polishing cream application machine

- Brushing machine with unit for application of hard wax on felt rollers

- Spraying cabin

- Unit for storing shoes during drying time

- Industrial robot

Polishing cream is applied manually in all shoe enterprises examined by the authors. On the market there is no polishing cream application machine available. Therefore, it was necessary to design and build a special machine. It consists of a cream application unit and a dosage control unit. Cream is applied to the shoe with a rotating soft sponge. An 
$\mathrm{AC}$ motor with built in gears was used to rotate the sponge at $3 \mathrm{rev} / \mathrm{sec}$. A dosage unit is composed of a polishing cream container and a pneumatic cylinder with an adjustable extension for the precise dosage of the polishing cream. The container is actually a large pneumatic cylinder, where the polishing cream is constantly under pressure in order to avoid air bubbles. The polishing cream is applied from the dosage control unit to the sponge through the rotating axis. The brushing machine used in our application is a modified standard shoe brushing and polishing machine with added unit for automatic polishing wax application directly on the felt rollers. The wax application unit consists of a stepper motor, which controls the wax movement, and the sensory system, which detects the brush radius and the quantity of the remaining wax. The brushing machine is equipped with its own PLC, which controls the rotation speed of the main brush motor, suction motors and the wax application unit. All components of the work-cell were modelled using the ROBCAD simulation system. Figure 5 shows the layout of the simulated wok-cell. Authors simulated different layouts of the finishing cell with different types of robots. An appropriate robot was selected taking into account measured maximum forces and torques during the manual polishing and required workspace. The selected industrial robot ABB 2400/16 meets all requirements. ROBCAD simulation has been used to estimate the average finishing cycle time and the number of the required storages for the shoes drying after the application of the polishing cream and/or spray solvent. It turned out that 18 storages are sufficient. They were mounted on the top of the polishing cream application machine and spraying cabin, as seen in figure 5 and 6. 


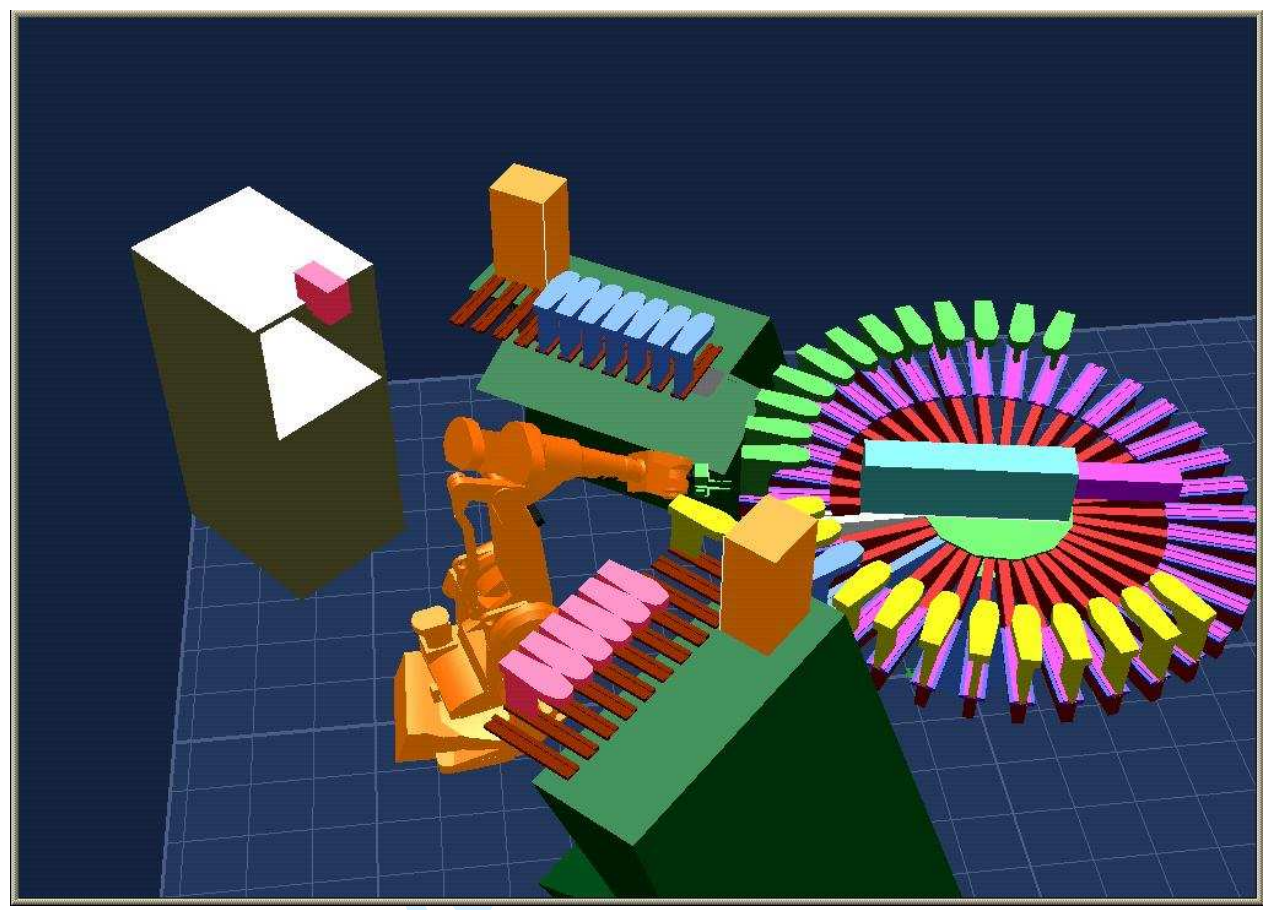

figure 5: Display of the simulated cell on ROBCAD

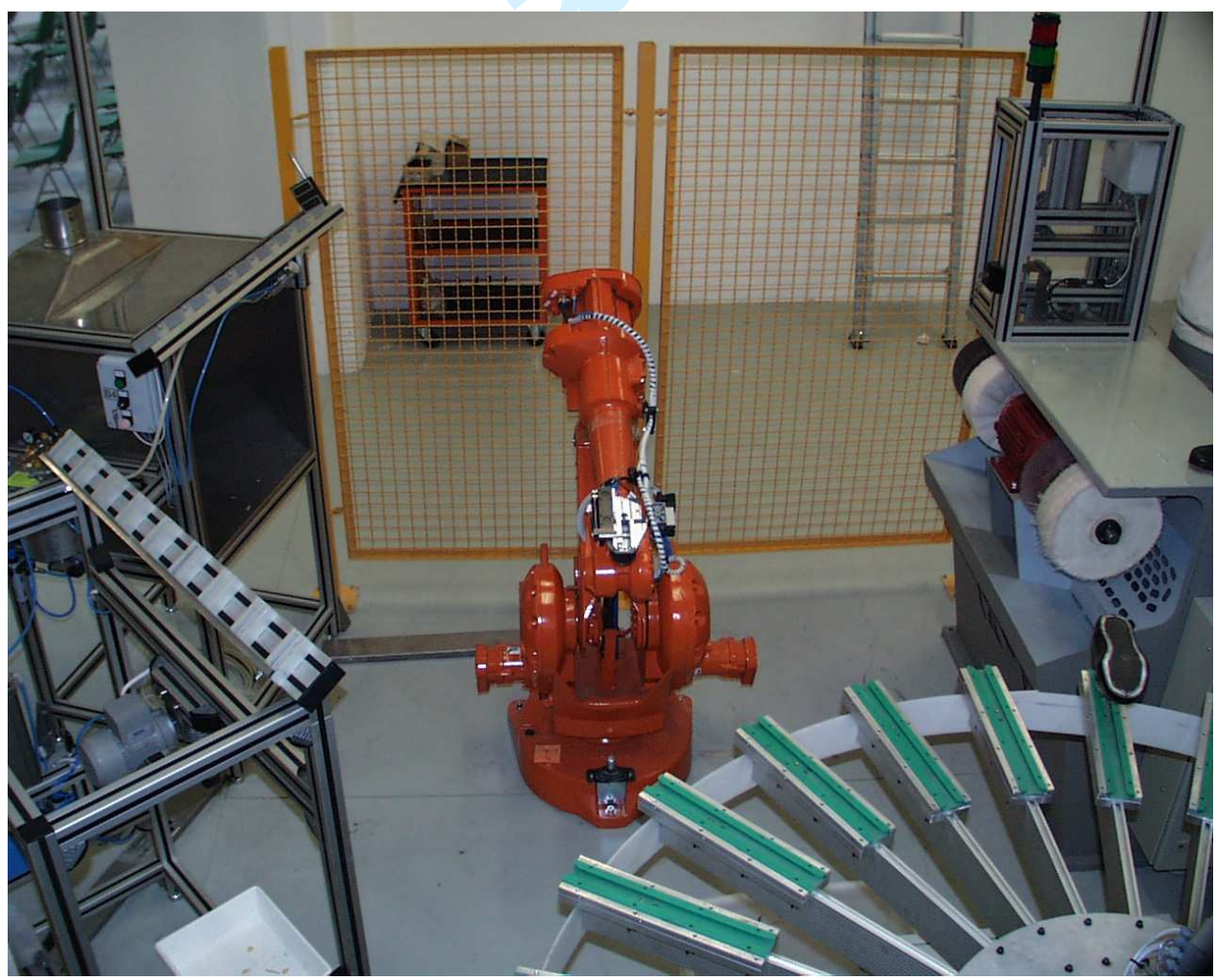

figure 6: Actual finishing cell 


\section{FINISHING CELL CONTROL}

The synchronisation between the finishing cell components is carried out with the main cell computer, which is a standard personal computer running on Windows XP operating system. The block diagram of the finishing cell control is presented in figure 7 . The main tasks of the cell controller are

- Communication-synchronization with the IPP production line control computer. Low level synchronization signals are exchanged with the production plant SCADA using the Profibus and the OPC server. High level synchronisation and exchanging of part programs is accomplished using TCP/IP protocol on Ethernet.

- Synchronisation of tasks in the finishing cell. The brushing machine PLC is connected to the control computer using the ProfiBus and the OPC server. The cell controller communicates with the robot controller using a serial line, the ProfiBus and the Ethernet. The cell controller sends to the robot macro commands for finishing operations such as "TAKE SHOE FROM STORAGE 2" or “BRUSH USING TRAJECTORY TEST.MOD” via the serial port. The robot controller uses the serial port to send the robot status. Trajectories that are used for polishing, brushing, creaming and spraying are defined in subprograms called modules. Modules are sent to the robot controller whenever they are required during normal finishing cell operation using the FTP protocol. The ProfiBus is used to map the internal status of the robot controller and digital inputs/outputs to the cell controller. In order to enhance the reliability of the setup two ProfiBuses were used - one for the communication between the finishing cell devices and one for the synchronisation of the finishing cell with the rest of the production plant (Zangiacomi 2004).

- Control of finishing operations. Finishing operations for each shoe are defined using a macro language, which allows the description of the shoe finishing technology. The macro language describes which finishing operations are necessary, which tools should be used (brushes, solvents, polishing creams,...), 
the rotation speed of the felt rollers, the quantity of the polishing cream, the drying time after the application of the polishing cream or spraying with solvents, etc. The robot controller optimises the task scheduling in the finishing cell in order to match as close as possible the required technology. Beside, it schedules dynamically shoes in the empty storages.

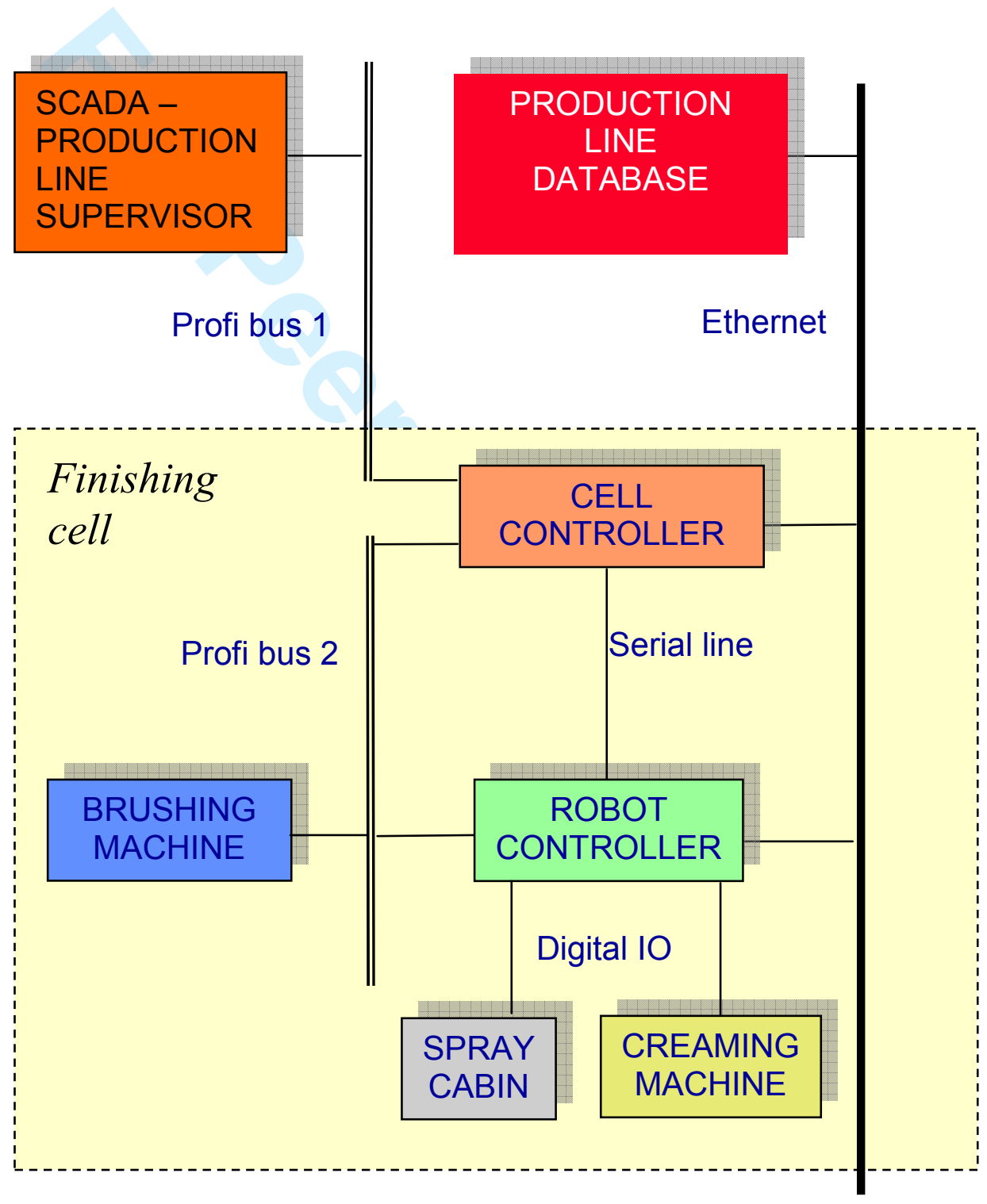

figure 7 : Block diagram of the finishing cell control 


\section{PREPARING OF FINISHING OPEARTIONS}

Customised mass production differs from the mass production because virtually any product item can differ from the previous one. Therefore, manual teaching and manual preparation of the manufacturing programs is not acceptable. The customised mass production requires that all production phases are prepared in advance during the design phase of the specific shoe model. Modification of the part programs for the specific shoe model, required for the customisation, has to be done automatically without any human intervention. Therefore, new CAD tools for finishing operations had to be developed.

Finishing operations CAD tools rely on the CAD shoe model, which is used for other manufacturing phases such as last grinding, material cutting, lasting, side roughing, etc (Paris 2004). They were implemented as a special toolbar in the PowerShape CAD modelling system by Delcam (Delcam 2004). Using PowerShape, the designer sketches the work trajectory on the shoe surface using one of 3 work tools - polishing brush, cream application sponge or spray gun.

In the robot application, the tool orientation is also very important. As default, the principal axis of the tool is aligned with the shoe surface normal. This criterion defines 2 of 3 orientation angles. The remaining third angle, which defines rotation around the tool principal axis has no influence on operations like spraying and cream applications, since the tool either rotates or it is axial symmetric. On the other hand, this angle defines the actual configuration of the robot and it must be controlled in such a way, that the robot does not reach the limits in the joint angle and/or singular configuration of the robot wrist. Therefore, the operator must be able to control and modify all 3 orientation angles, as seen in figure 8. In order to facilitate the trajectory sketching, the CAD tool allows interactive visualization of the path covered by the selected work tool. Despite of all CAD tools, the definition of the robot trajectory is not an easy task. Actually, it is impossible to predict if the desired path will violate the robot joint limits or if a collision of the robot with the environment will occur. Although there are many off-line programming environments available on the market, which can predict collision or 
excessive joint values, trajectory checking and verification is time demanding since it requires the migration of the trajectories from PowerShape to the off-line programming. Currently, the trajectories are defined basing on trail-and-error method, which is time consuming. However, the finishing process trajectories do not differ excessively from one shoe model to the other, as long as they belong to the same type of the shoe, such as men's shoe, sandals, etc. Therefore, the technique of projecting appropriate trajectory templates to the shoe model can be applied and only small modifications are needed in order to meet specific requirements.

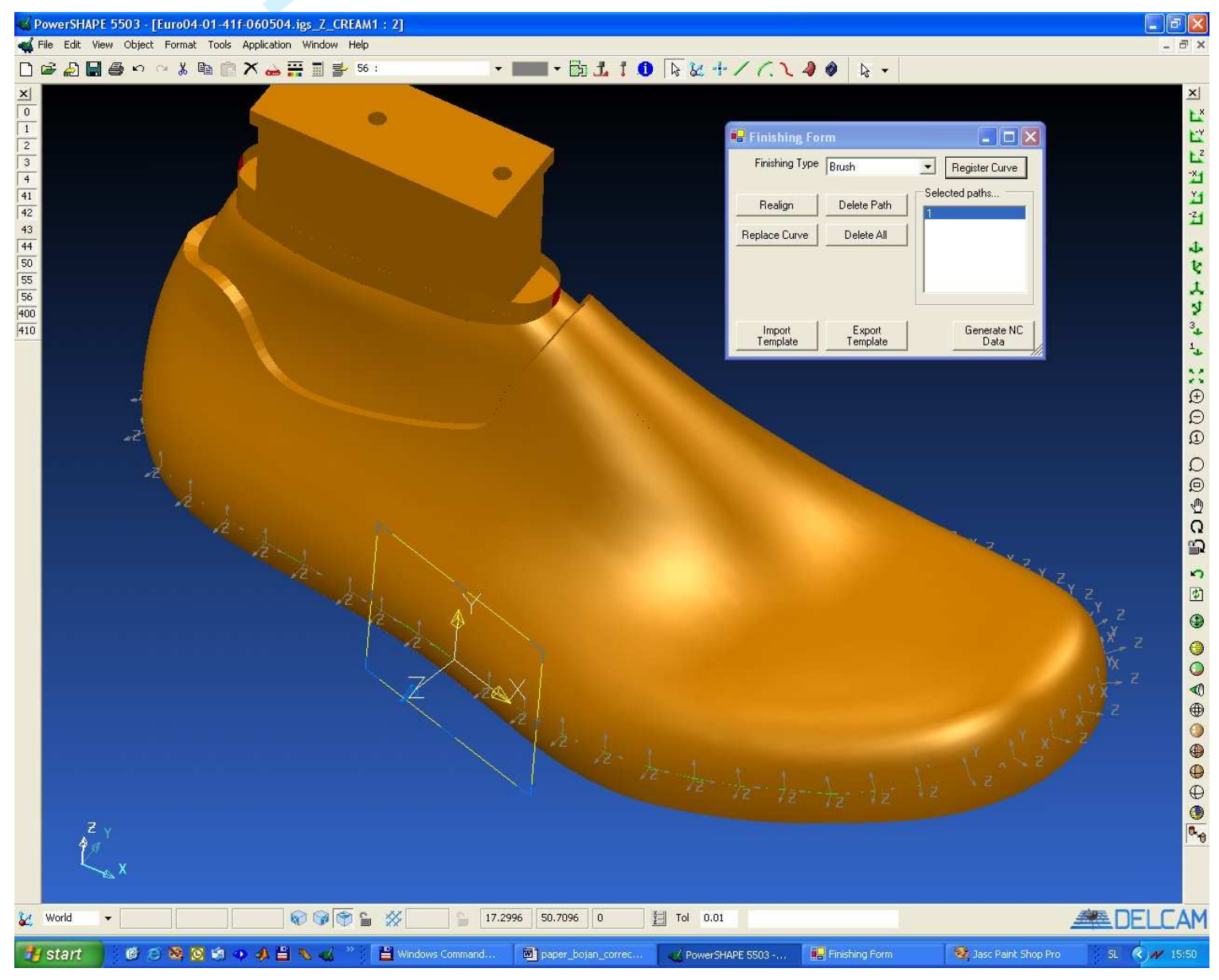

figure 8 : Trajectory generation with PowerShape CAD program 


\section{OPTIMIZATION OF ROBOT TRAJECTORIES USING KINEMATIC REDUNDANCY}

One of the main problems in automatic trajectory generation is the inability to assure that the generated trajectory is feasible using a particular robot, either because of possible collisions with the environment or because of the limited workspace of the particular robot. Limitations in the workspace are usually not subjected to the tool position, but rather to the tool orientation. Another severe problem are wrist singularities, which can not be predicted in the trajectory design phase on a CAD system.

For a given task, the obstacle avoidance can be accomplished only if the robot is kinematicaly redundant. Note that the degree of redundancy depends on the task the robot is performing. For example, 6 D.O.F robot is kinematicaly redundant for spraying and creaming operations. Due to the circular shape of the cream application brush and spray beam, roll angle or the robot is free to choice. For brushing operations, there is another type of redundancy due to the circular shape of felt rollers. Namely, the tool centre point is not restricted to be a fixed point, rather it can be freely chosen at the circumference of the tool. This redundancy is illustrated in Fig 9, where angle $\varphi$ is free to choose. Unfortunately, in general one degree of redundancy is not enough to satisfy simultaneously all secondary tasks - obstacle avoidance, singularity avoidance and preserving the joint angles within their physical limits. More flexibility is offered by the fact that for some tasks it is not necessary to assure strict orientations of the tool. This can be interpreted as two additional degrees of redundancy. 
Nemec, Zlajpah

Robotic cell for custom finishing operations

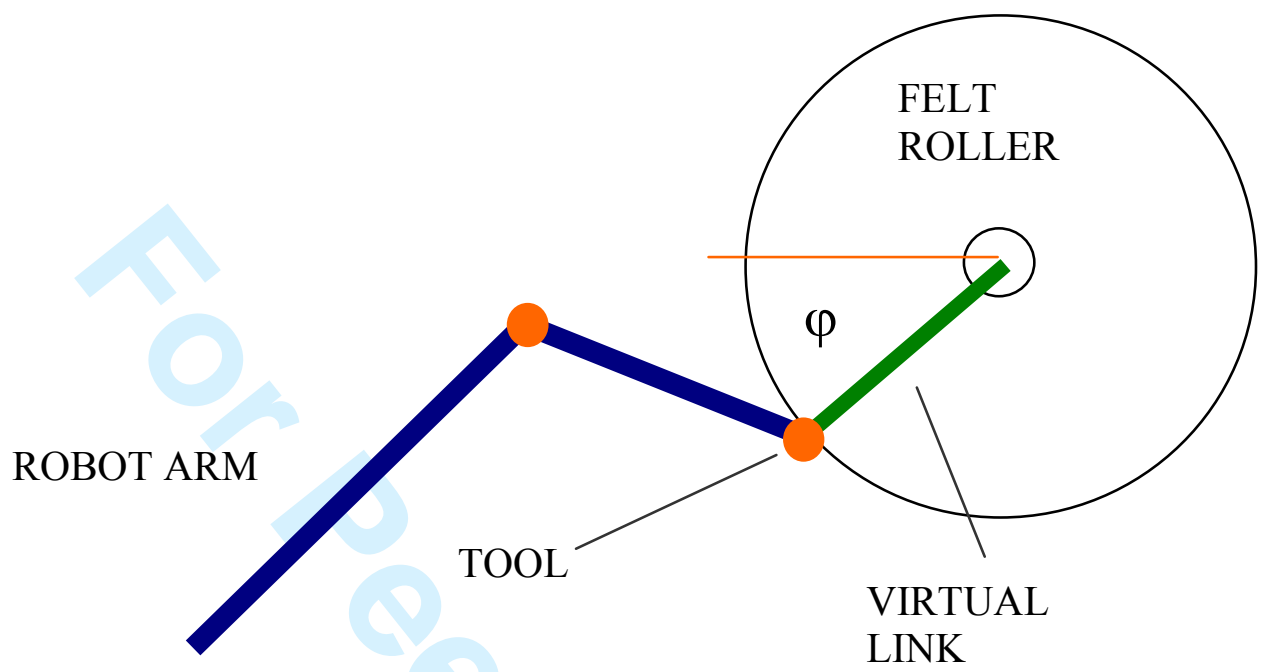

figure 9: Kinematic redundancy due to the circular shape of the brush tool

The following equation describes the kinematics of the redundant robot (Nenchev89)

$\dot{q}=J^{T} \dot{x}+N \phi, N=\left(I-J^{+} J\right)$

where $\dot{q}$ is joint velocity vector $(n \times 1), J$ is the $(m \times n)$ Jacobian matrix, $J^{+}$is the Moor-Penrose pseudo-inverse of the Jacobian matrix, $\dot{x}$ is task (Cartesian) velocity vector $(m \times 1), N$ is the null space matrix of the redundant manipulator $(n \times n)$ and $\phi$ is an arbitrary velocity vector $(n \times 1)$. Here, $n$ denotes the number of joints and $m$ the number of task coordinates. Let $p$ be the desired cost function, which has to be maximized or minimized. Then using the velocities

$\phi=\left(\frac{\partial p}{\partial q_{1}}, \frac{\partial p}{\partial q_{2}}, \ldots, \frac{\partial p}{\partial q_{n}}\right) k$

in Eq. (1) maximizes cost function $p$ for any $k>0$ and minimizes cost function $p$ for any $k<0$ (Yosikawa96), where $k$ is an arbitrary scalar that defines the optimization step. Authors have chosen such $p$ that maximises the distance between the obstacle point and the collision point on the robot link or robot work object, maximizes the distance 
between the current and the singular configuration of the robot and maximizes the distance in joint coordinates between current joint angle and joint angle limit. It is favourable that the robot tool orientation is as close as possible to the desired configuration. Therefore, the distance between the desired orientation angles and the actual obtained orientation angles will be also minimised.

Let denote the Jacobian and the task coordinates of 6-D.O.F robot as

$J=\left[\begin{array}{l}J_{p} \\ J_{r}\end{array}\right], \quad x=\left[\begin{array}{l}x_{p} \\ x_{r}\end{array}\right]$,

where suffix $p$ and $r$ are related to the positions and orientations, respectively. Let define the cost function as a sum of four cost functions $p=p_{A}+p_{L}+p_{S}+p_{o}$, where $p_{A}$ denotes cost function for obstacle avoidance, $p_{L}$ cost function for avoiding joint limits, $p_{S}$ cost function for singularity avoidance and $p_{O}$ cost function for keeping the tool orientation as close as possible to the desired orientations. The selected cost function for obstacle avoidance is (Kathib86, Nemec00)

$p_{A}=V\left(x_{c}-x_{o}\right)=V d$,

where $V$ denotes vector of potential field pointing away from the obstacle, $x_{c}$ is point on the robot or tool closest to the obstacle, $x_{o}$ is an obstacle points and $d$ is the distance between these two points. The cost function for the joint limits avoidance is defined as $p_{L}=\left\{\begin{array}{c}\left(q_{\max }-q\right)^{2},\left|q_{\max }-q\right|<\varepsilon \\ 0 \\ \left(q_{\min }-q\right)^{2},\left|q_{\min }-q\right|<\varepsilon\end{array}\right\}$,

where $\varepsilon$ is a positive constant defining the neighbourhood of joint limits. A similar cost function for preserving the tool orientation as close as possible to the desired orientation is

$$
p_{O}=\left(x_{r d}-x_{r}\right)^{2},
$$

where $x_{r d}$ denotes desired orientation vector.

Singularity avoidance strategy was accomplished by the maximisation of the manipulability index. Manipulability index is a common measure of a manipulator's 
Nemec, Zlajpah

Robotic cell for custom finishing operations

ability to move its end effector from a given configuration (Yosikawa90). A suitable measure can be defined as

$p_{S}=\sqrt{\left|J J^{T}\right|}$

Then, the joint velocities for our task are calculated as

$\dot{q}=J_{p}^{T} \dot{x}_{p}+N \phi, N=\left(I-J_{p}^{+} J_{p}\right)$

$\phi=k_{A} J_{p}^{03} V d-2 k_{L}\left(q_{L}-q\right)-2 k_{O}\left(x_{d r}-x_{r}\right) J_{r}-2 k_{s} \frac{\partial J}{\partial q} J^{T}$

Matrix $J_{p}^{03}$ is Jacobian matrix calculated from the robot base to the robot wrist. Scalars $k_{A}, k_{L}, k_{S}$ and $k_{O}$ are arbitrary chosen positive constants defining the optimization step. In real implementation, $k_{A}$ and $k_{L}$ are set to zero if the observed point is enough away from the possible collision points and joints are far away from their limits, respectively. Similar, the last term of $\phi$ is not computed if the manipulability index is large enough. Unfortunately, the partial derivative $\frac{\partial J}{\partial q}$ is not easy to calculate. However, as the trajectory optimization is not performed on-line, the numerical derivative of the manipulability measure $p_{s}$ can be used instead of $\frac{\partial J}{\partial q}$. Vector $q_{L}$ denotes the physical joint limit and its value can be $q_{\min }$ or $q_{\max }$. The optimisation procedure defined with equation (9) is repeated until the desired configuration is found. It might happen, that the procedure does not converge, since the requirements are contradictory. For an example, such a situation occurs when the collision avoidance pushes joints toward the joint limits. Consequently, a feasible solution does not exist.

\section{OPTIMIZATION OF ROBOT TRAJECTORIES USING VARIABLE TOOL CENTRE POINT}

In general, it is desired that the robot joint motion is minimized during the execution of the given task. Therefore, the minimisation of the joint motions could be added as additional criteria in the trajectory generation using kinematic redundancy. It turned out, 
that more straightforward and efficient was the trajectory optimization using the variable tool centre points (TCP). An illustrative example is presented in the figure 10. Suppose that a brushing trajectory is defined with two points $\mathrm{A}$ and $\mathrm{B}$ on the shoe and that the normal vector to the shoe surface at these contact point must be aligned with the TCP (tool centre point). A fixed TCP (as shown on the centre of the figure 10) results in a large movement of the shoe consequently and in a large movement of the robot. In the second case (as displayed on the right side of the figure 10), two different TCP-s are used and as a results the shoe movement in very moderate.

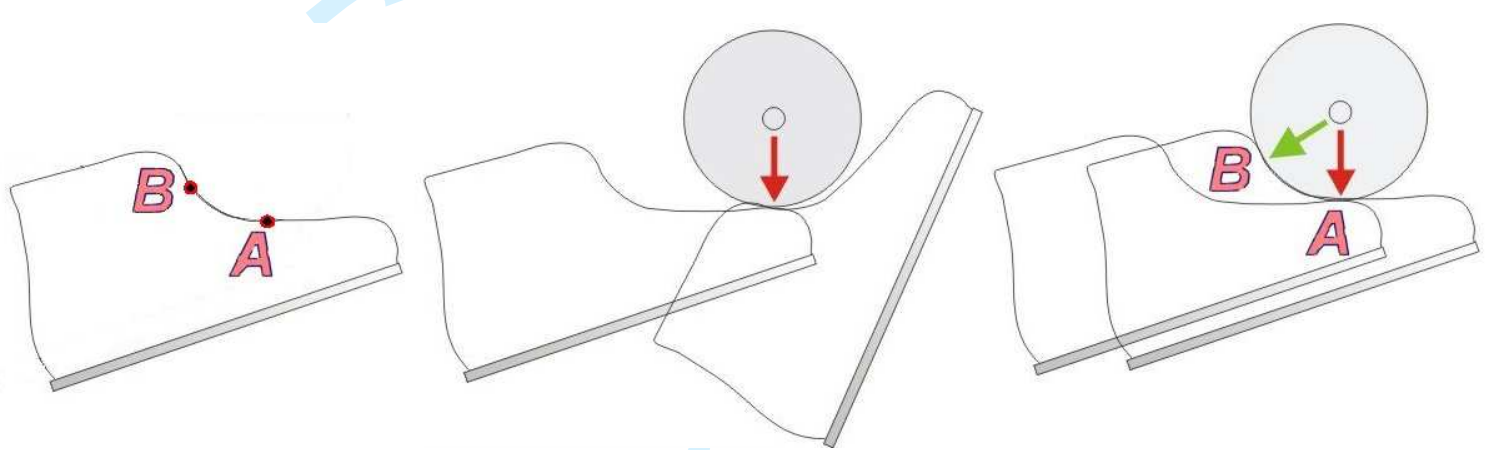

figure 10 : Shoe brushing with fixed TCP and with TCP adaptation

Unfortunately, the selected industrial robot does not allow changing the TCP during the movement along a given trajectory. Therefore, it is necessary to transform the trajectory with respect to the 'virtual' TCP. The transformation of each point of the working trajectory is carried out in two steps

- Find the closest contact position, which minimises the movement from the current position.

- Calculate virtual points according to the actual TCP

For the concave trajectories the optimization can be simplified using to the following procedure. Let describe the desired trajectory $t$ with a series of points, $t=\left(x_{1}, x_{2}, x_{3}, \ldots x_{k}\right)$ and let $n_{i}$ be the normal to the shoe surface at the trajectory point $x_{i}$. In our case $n_{i}$ should be aligned with the $z$ axis of the robot tool. The orientation of the robot in the point $p_{i}$ can be represented with a quaternion $Q_{i}$ 
(Shoemake 85, Chou 92, Corke 02). The quaternion $Q_{y i}$ is defined so that it represents the transformation which aligns $y$ axis of the frame $x_{i}$ with the axis of the rotation of the felt roller. Then, the transformed point can be described as

$$
\begin{aligned}
& Q_{w i}=Q_{y i}^{-1} \\
& x_{w i}=x_{i}+r Q_{w i}\left(Q_{y i} V_{z}-V_{z}\right)
\end{aligned}
$$

$$
V_{z}=\left[\begin{array}{l}
0 \\
0 \\
1
\end{array}\right]
$$

where $r$ denotes the felt roller radius. The resulting trajectory has to be transformed into the form which can be executed by the robot. Since ABB robot requires quaternions robot orientation, the trajectory transformation using the above equations to the RAPID robot language is straightforward.

Generation of finishing trajectories is done in the following steps

- Manual design of finishing trajectories using "Finishing tool" in PowerShape CAD modeller

- Automatic optimization using variable TCP if the trajectory is dedicated to the brushing of the shoe toe

- Automatic optimization using kinematic redundancy of the robot

- Automatic generation of the robot program and the finishing cell program

- Verification of the robot program using the robot graphical simulation system

- Downloading of the robot program and the cell program to the cell controller

Verification of the robot program using the robot graphical simulation system is necessary only when preparing trajectories for a new type of the shoe. 


\section{CALIBRATION}

An important aspect of the finishing cell is also the calibration. The calibration includes the calibration of the robot itself and the knowledge about the positions of all cell components in world coordinates. Some positions, like storage positions, remain fixed during the work cycles and have to be updated only if the machine itself is being moved. Others, like brushes and TCPs, constantly change due to the material wearing out. A special calibration program, which uses the robot as a measuring device, was developed to define fixed positions. For this purpose, a special pointer robot tool was mounted on the robot tip. From three calibration points, which were measured on each machine, the calibration program calculates the position and the orientation of all contact points and modifies the robot program. On the contrary, the TCP of all brushes has to be measured constantly during the normal robot operations. To measure the brushes a photocell probe mounted on the robot gripper is being used.

\section{CONCLUSIONS}

The paper deals with the development of the automated cell for finishing operations in the shoe production industry. The automated finishing cell consists of an industrial robot, a brushing machine, a creaming machine and a spray cabin. Up to now, the finishing operations were done manual. Therefore, it was necessary to analyze manual operations required for shoe finishing. Beside the motions, the contact forces pay an important role in finishing operations. It has been shown, that due to the compliant characteristics of the brushes and felt rollers, force control of the industrial robot is possible without force sensor. One of the main features of the automated cell is the flexibility and the ability to handle new types of shoes without any manual teaching process. All finishing operations are defined in the design phase using a CAD system. It turned out that the existing CAD tools which are used for operations like milling, grinding, etc. are not appropriate for robot based finishing operations. Therefore, new CAD tools had to be defined. The trajectory generation module includes trajectory optimization, which avoids possible collisions between the robot wrist and the robot tool, avoids joint limits and avoids the 
wrist singularity. The developed production cell is the first successful approach to the automation of the shoe finishing processes. The evaluation phase of the project was finished in 2004 in IPP in Vigevano, Italy, and it demonstrated the efficiency of the developed approach. It will serve to test and modify the technology of the automated finishing processes. Based on this experience new finishing cells can be designed, which will meet the specific requirements of the shoe manufacturers. Authors expect that polishing, cream application and spraying will be realized as three production cells, each with its own robot. This will increase the productivity and the quality of the finishing process.

\section{REFRENCES}

ITIA - CNR Institute of Industrial Technologies and Automation, 2003, Development of the processes and implementation of management tools for the Extended User Oriented Shoe Enterprise, Project description

Dulio, S. Boër, C.B. 2004, Integrated production plant (IPP): an innovative laboratory for research projects in the footwear field, Int. Journal of Computer Integrated Manufacturing, 17 (7) 601-611.

Nemec, B. Lenart, B. Žlajpah, L. 2003, Automation of lasting operation in shoe production industry., International conference on industrial technology , IEEE ICIT 2003, Maribor, Slovenia, December 10-12, Proceedings. Piscataway: IEEE, pp. 462-465.

Nemec, B. et all 2003, Technology fostering individual, organisational, and regional development : an international perspective. In Brandt, D. Kompetenzentwicklung 2003 : Technik, Gesundheit, Ökonomie. Münster (New York : Waxmann Muenster), pp. 19-70.

Taylor, P.M., \& Taylor, G.E. 1988, Garments and Shoe Industry-Robots, In Encyclopedia of Robotics, ed. Dorf R.C., Nof S.Y., (Wiley Interscience), pp. 587-591

Furukawa,T. Rye, D.C. Dissanayake, M.W.M.G. and Barratt, A.J. 1996, Automated Polishing of an Unknown Three-dimensional Surface, Robotics \& Computer-Integrated Manufacturing, 12(3), pp. 261-270.

Zhao J., Saito, K. Kondo, T. Narahara, H. Igarashi, S. Sasaki, T. and Zhang, L. 1995, A New Method of Automatic Polishing on Curved Aluminum Alloy Surface at Constant Pressure, Int. J. Mach. Tools Manufact. 35, (12), pp. 1683-1692. 
Nemec, Zlajpah

Robotic cell for custom finishing operations

Tam, H.Y. Lui, O.C.H. Mok, A.C.K. 1999, Robotic Polishing of Free-Form Surfaces Using Scanning Paths, J. of Materials Processing Technology, 95 , pp. 191-200.

Akbari, A.A. Higuchi, S. 2001, Optimum Machining Conditions for Mirror Polishing of Aluminum Alloy Using a Robot, JSME International Journal, Series C, 44(3) , pp. 842847.

Baseñez, L. Rosell, J. Robotic Polishing Systems, IEEE Robotics \& Automation Magazine, 12(3), pp 35-43

Hogan, N. 1985, Impedance Control: An Approach to Manipulation: Part 1: Theory, Part 2: Implementation, Part 3: Applications, Trans. of ASME J. of Dynamic Systems, Measurement, and Control

Zangiacomi, A. Zhijian, L. Sacco, M. Boër, C.R. 2004, Process planning and scheduling for mass customised shoe manufacturing, Int. Journal of Computer Integrated Manufacturing, 17 (7) 613-621.

Paris, I. Handley, D. 2004, CAD usage and knowledge base technology in shoe design and development, Int. Journal of Computer Integrated Manufacturing, 17 (7) 595-600.

http://www.delcam.com/, Solutions for Shoes/footwear, Delcam 2004

Nenchev, D. N. 1989, Redundancy Resolution through Local Optimization: A Review; J. of Robotic Systems, 6(6), pp. 769-798

Shoemake, K. 1985, Animating rotation with quaternion curves, in Proceedings of ACM SIGGRAPH, (San Francisco), pp. 245-254

Chou, J.C.K. 1992, Quaternion Kinematic and Dynamic Differential Equations, IEEE Trans. Robots. 8, 1, pp. 53-64.

Corke, P.I. 2002, A robotics toolbox for MATLAB, IEEE Robotics \& Automation Magazine Volume: 3, 1, pp. 24 -32

Khatib, O.:1986, Real-time obstacle avoidance for manipulators and mobile robots, J. of Robotic Systems, 5(1), pp. $90-98$

Nemec, B. Zlajpah, L. 2000: Null velocity control with dynamically consistent pseudoinverse, Robotica, 18, pp 513 - 518

Yoshikawa, T. 1990, Foundations of robotics: analysis and control, MIT Press.

Yoshikawa, T., 1996, Basic optimization methods of redundant manipulators, Laboratory Robotics and Automation, 8(1), pp. 49 - 90 


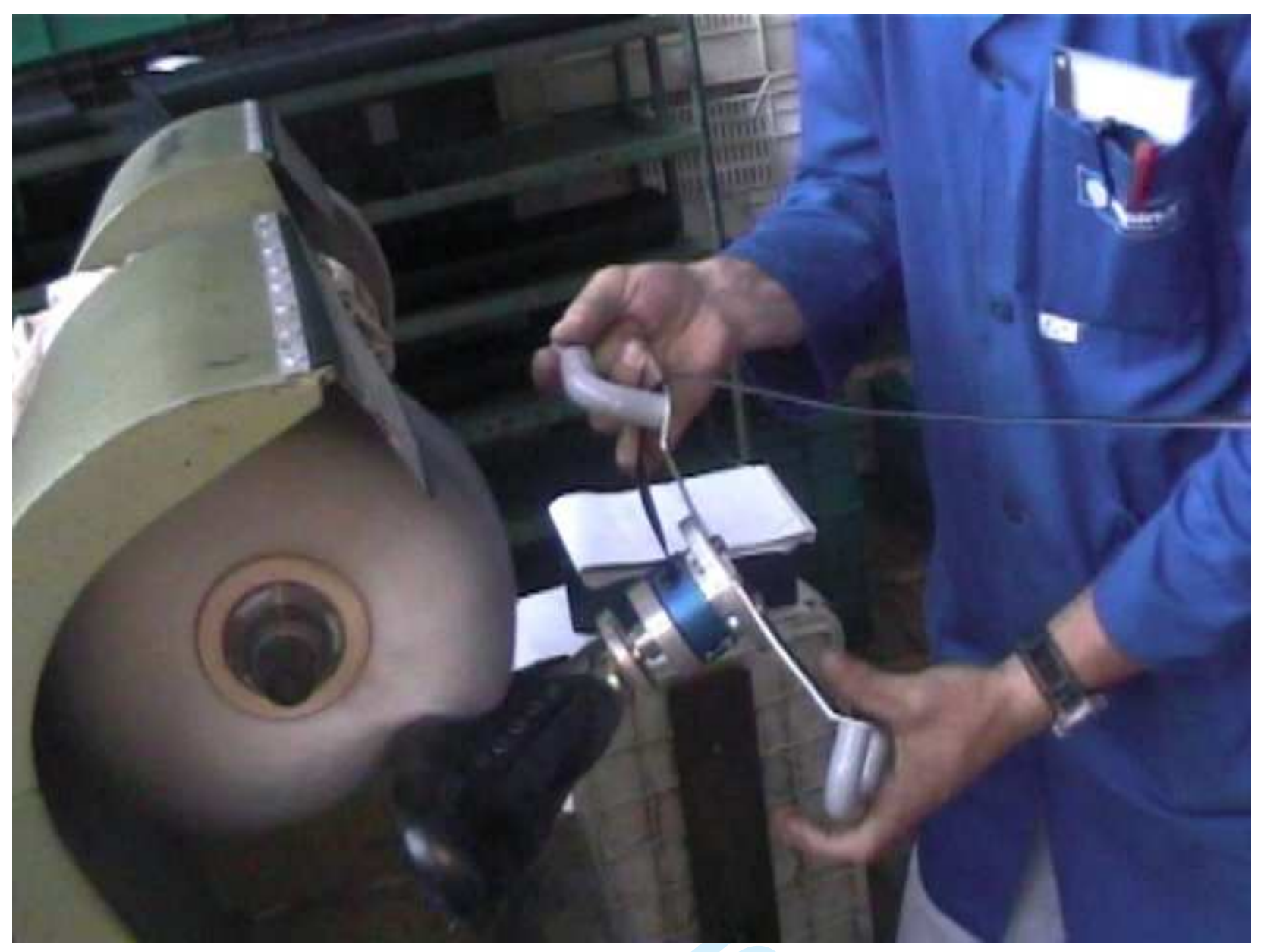

Figure 1 


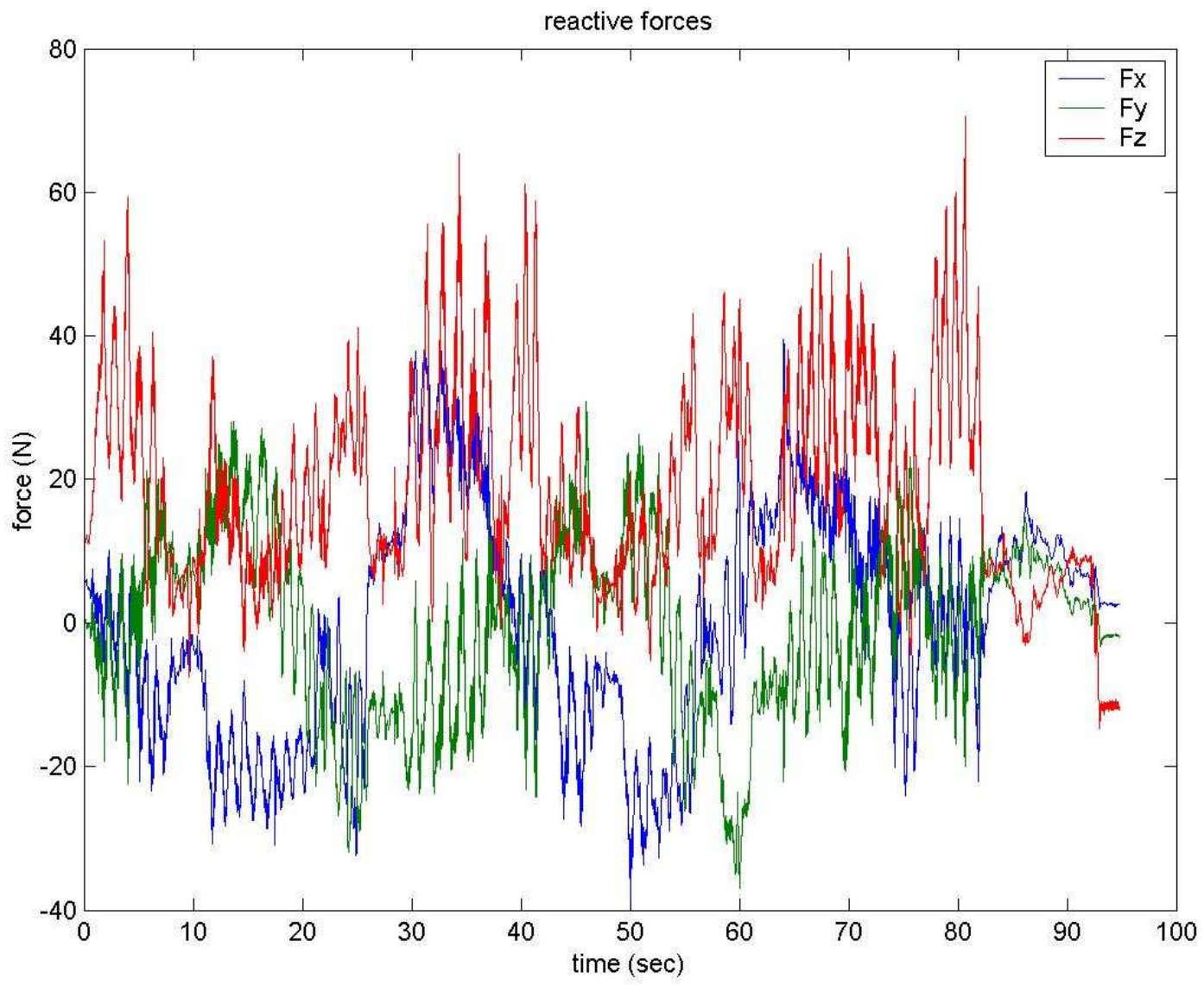

Figure 2 


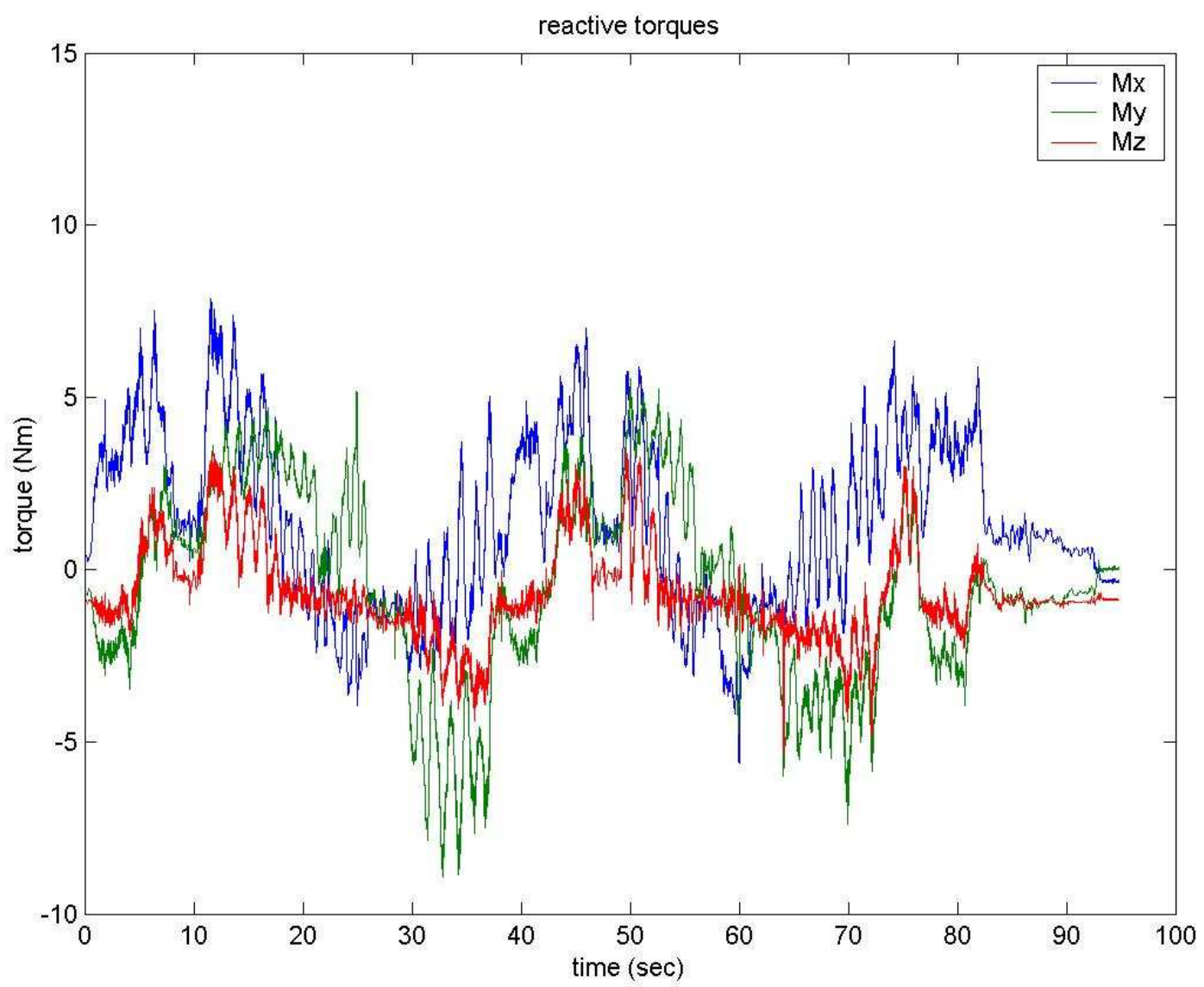

Figure 3 


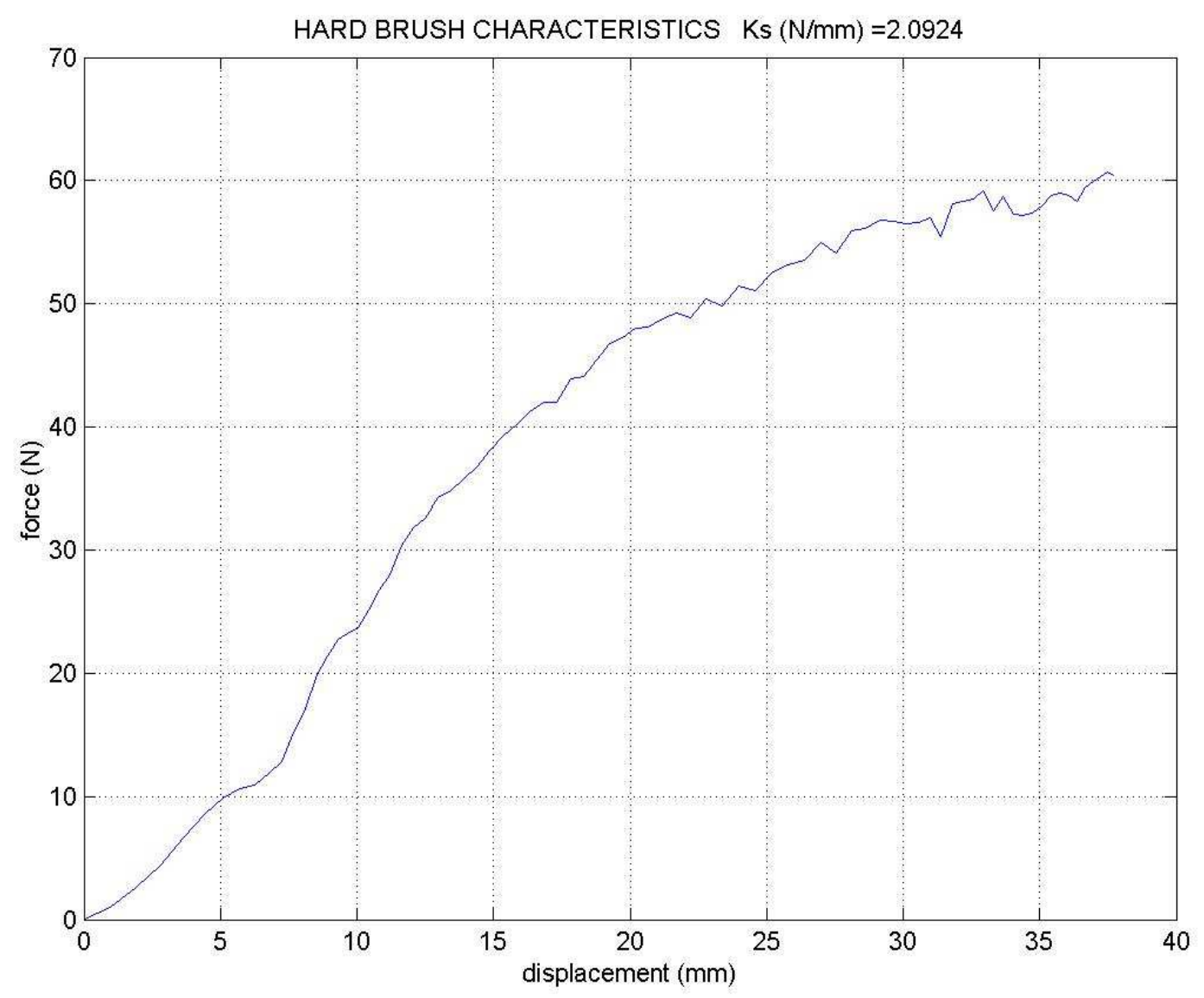

Figure 4 


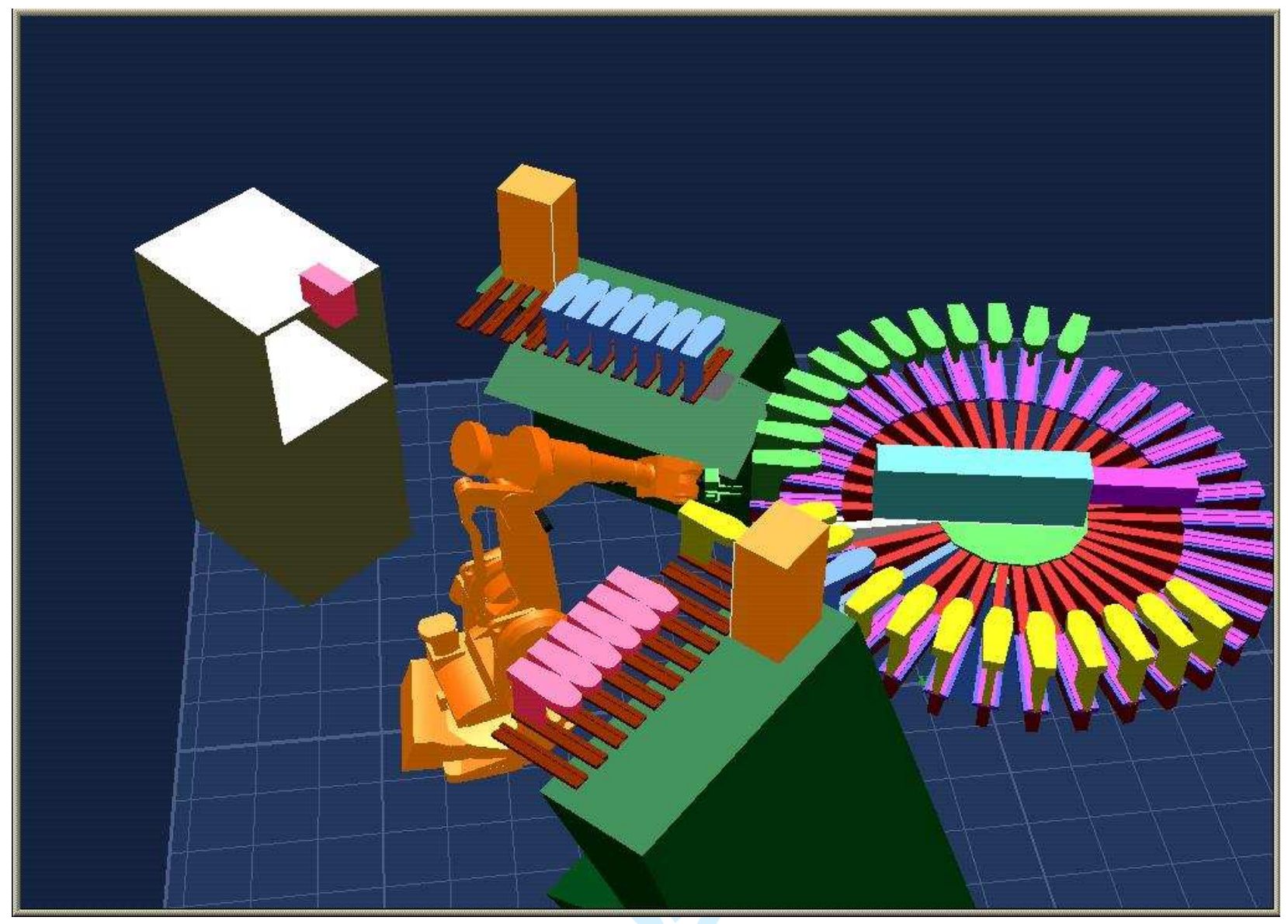

Figure 5 


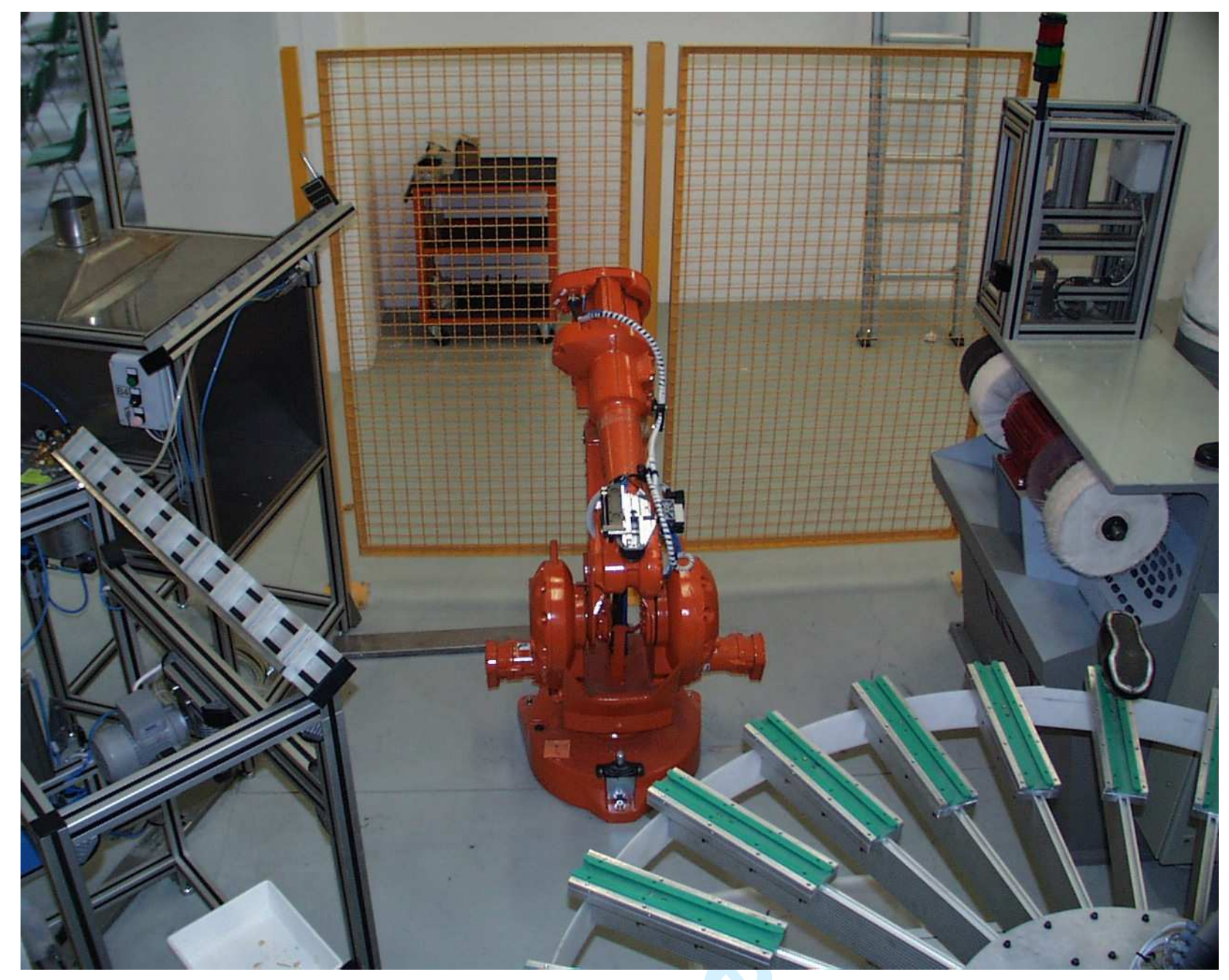

Figure 6 


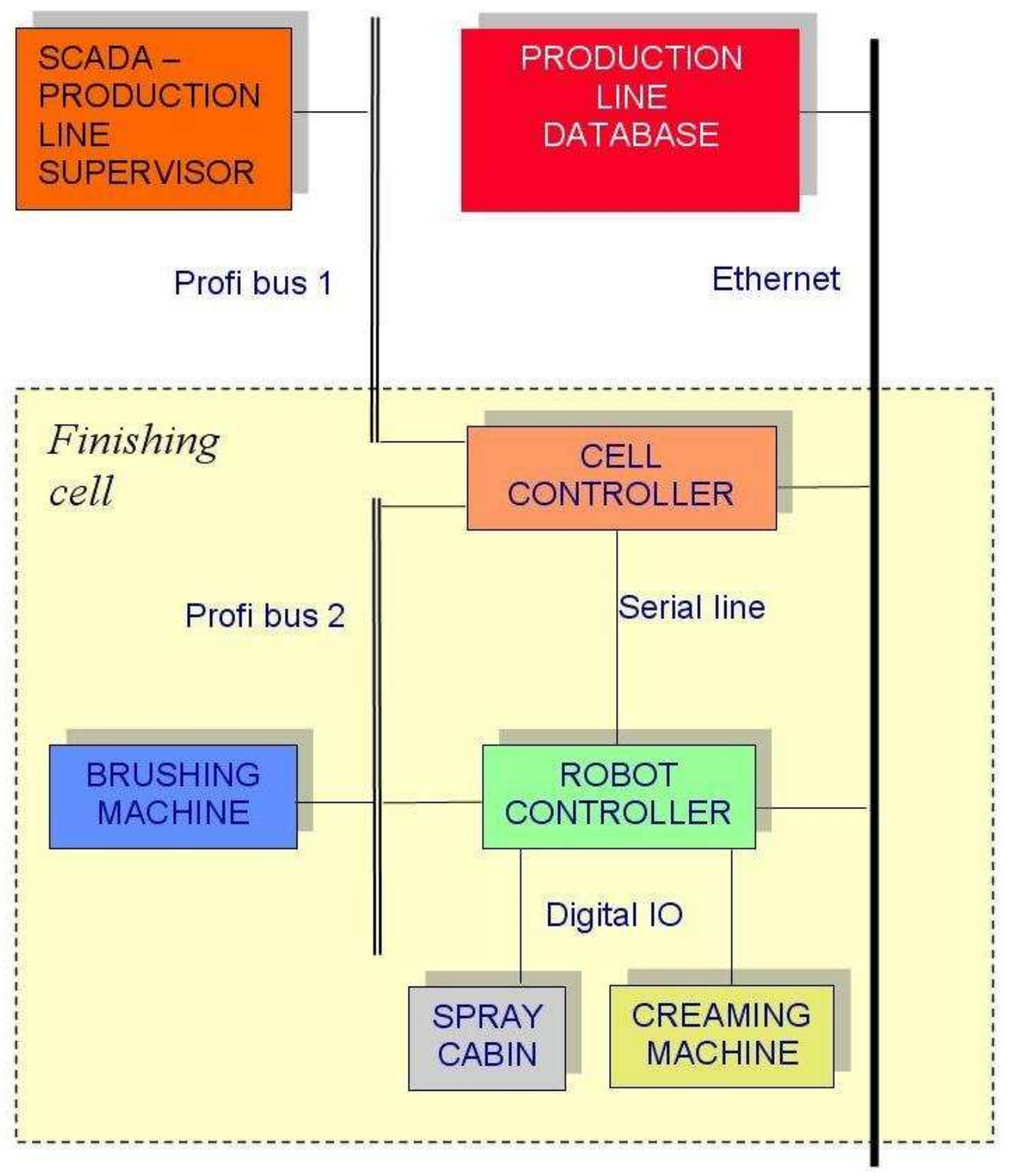

Figure 7 


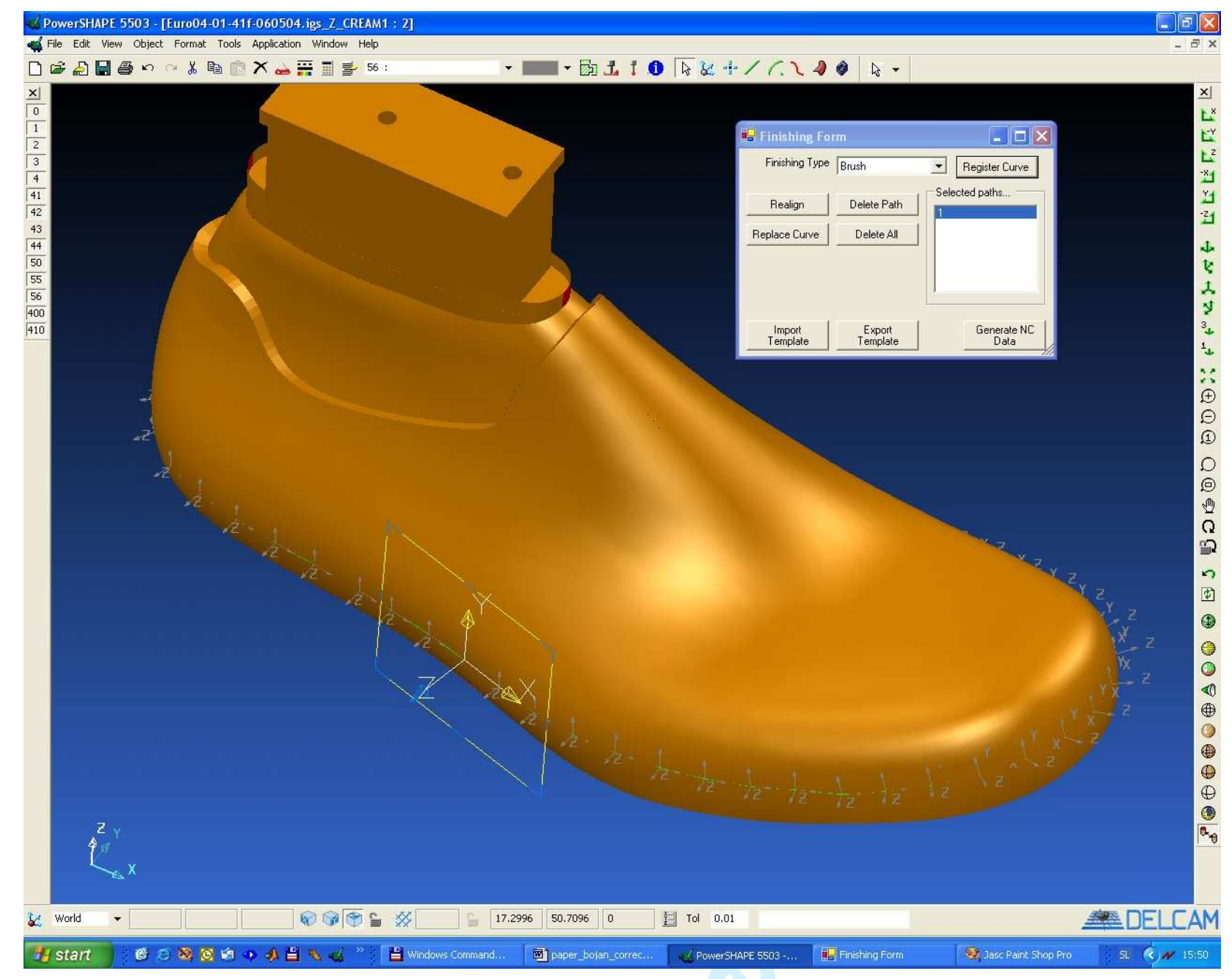

Figure 8 


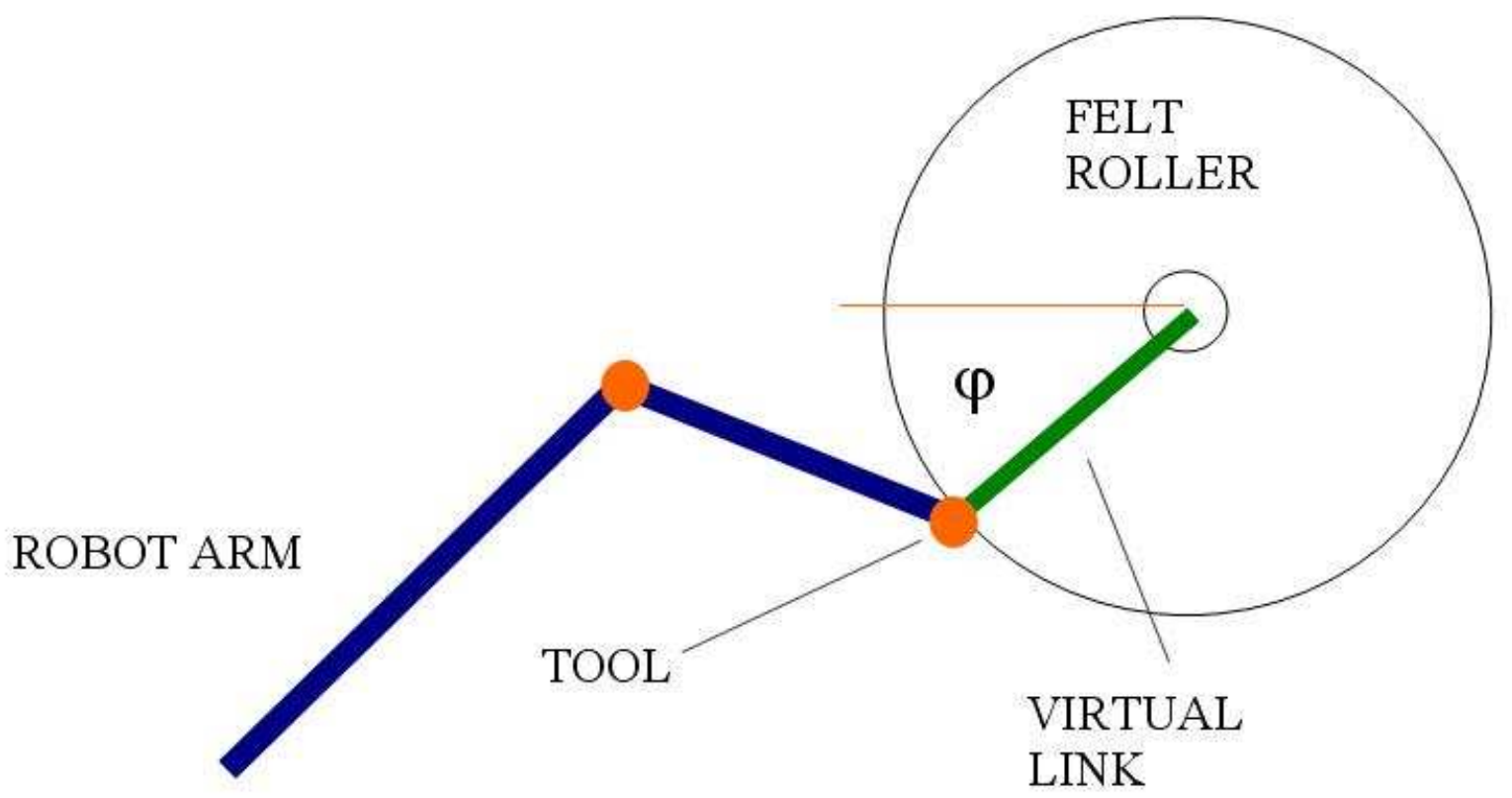

Figure 9 


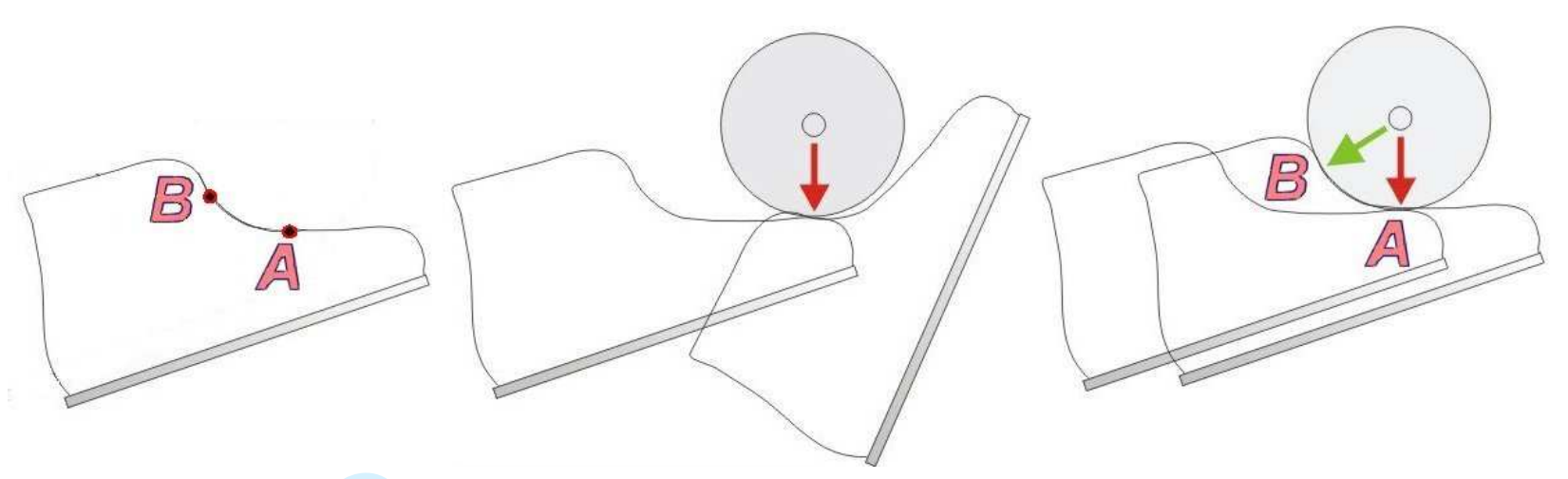

Figure 10

URL: http://mc.manuscriptcentral.com/tandf/tcim Email:ijcim@bath.ac.uk 